\title{
Tea Tree Oil versus Chlorhexidine Mouthwash in Treatment of Gingivitis: A Pilot Randomized, Double Blinded Clinical Trial
}

\author{
Francesca Ripari ${ }^{1}$ Alessia Cera ${ }^{1}$ Monica Freda ${ }^{1}$ Giulia Zumbo ${ }^{1}$ Francesca Zara ${ }^{1}$ Iole Vozza \\ ${ }^{1}$ Department of Oral and Maxillo facial Sciences, Sapienza \\ University of Rome, Rome, Italy \\ Address for correspondence Iole Vozza, DDS, PhD, Department of \\ Oral and Maxillo facial Sciences, Sapienza University of Rome, Via \\ Caserta 6-00161, Rome, Italy (e-mail: iole.vozza@uniroma1.it).
}

Eur J Dent 2020;14:55-62

\begin{abstract}
Objective The study evaluated the efficacy of tea tree oil for the treatment of gingivitis.

Materials and Methods The tea tree oil was administered in the form of mouthwash and then compared with a mouthwash with chlorhexidine $0.12 \%$. Both treatments were domestic and lasted for 14 days. Patients were chosen according to random criteria, aged between 18 and 60 years, and who showed a clinically evident gingivitis. In clinical evaluation, the following clinical criteria were taken into consideration: gingival index $(\mathrm{GI})$, plaque index (PI), bleeding index (BI), probing depth (PD), the presence of dental dyschromia, and the presence of taste alteration. The subjects were evaluated before (T0) and after the treatment (T1), and the data collected for each patient were recorded on a periodontal chart.

Results The comparison showed that tea tree oil offered a better improvement in the evaluation of PI, BOP, and PD; furthermore, it did not cause dental dyschromia and taste alteration. In group A, treated with tea tree oil, PI decreased from 53.25 to $5.50 \%$ and BI from 38.41 to $4.22 \%$. In group B, treated with chlorhexidine PI decreased from 47.69 to $2.37 \%$ and $\mathrm{BI}$ from 32.93 to $6.28 \%$. Instead, the subjects using chlorhexidine

Keywords

- gingivitis

- tea tree oil

- chlorhexidine

- oral hygiene

$0.12 \%$ blamed a distaste for the product that caused a slight taste alteration; $20 \%$ of them showed iatrogenic dental dyschromia.

Conclusions The collected data showed the efficacy of both treatments. Although further research works will be necessary, this study showed that tea tree oil could be an effective nontoxic substitute for the therapy of gingivitis.
\end{abstract}

\section{Introduction}

Health of oral cavity is associated with the presence of different microorganisms that may affect development of gingivitis and periodontitis. ${ }^{1,2}$ There is high-quality evidence of a large reduction in dental plaque with chlorhexidine mouth rinse used as an adjunct to mechanical oral hygiene procedures. ${ }^{3}$ Over the past decades, alternative medicine has proved to be more popular. Natural remedies are increasingly used, being considered effective substitutes of drugs in case of light or medium entity problems and possible auxiliary to drugs for serious entity problems. ${ }^{4-7}$
Stating this, it is possible because active principles extracted from plants have been, and still are, objects of in vitro studies, to better understand their therapeutic properties and their effect on the human body. A class of natural remedies is represented by essential oils and their use for therapeutic purposes dates back to ancient times, due to their strong anti-inflammatory and antiseptic activity demonstrated by several studies.-12

Recently, in the phytotherapeutic field, an essential oil is increasingly trending: tea tree oil. By virtue of its properties, it is becoming more famous and is getting utilized in dermatology, oncology, and dentistry. ${ }^{13-20}$ 
Tea tree oil is recognized as one of the most well-known essential oils and is also called "oil of the Tea tree" or "Melaleuca essential oil." It is derived from the distillation of the leaves of the Melaleuca alternifolia tree. This plant belongs to the family of Myrtaceae, which are arboreal plants hailing from Australia. Indigenously, it is defined as "the most versatile healer of nature."

Several studies ${ }^{21-23}$ reported its powerful antimicrobial activity in the medical field.

In the study of Carson et al, ${ }^{11}$ two components giving the oil its phytotherapeutic properties were identified: terpineol-4 and 1,8-cineol. According to the international standard ISO, the terpineol content in the substance does not have to be lower than $30 \%$, and the cineol does not have to be more than $15 \%$. The percentage ratio is important as cineol constitutes the irritating and toxic component of the oil and needs to be balanced by the terpineol to obtain the beneficial properties without complications. ${ }^{24,25}$

In the same study, the antimicrobic capacity of the oil was analyzed and the spectrum of microorganisms on which it has effect was identified, finding among them also the bacteria that colonize the oral cavity.

To corroborate the spectrum of action represented by these data, Penfold et al compared the oil to a strong antiseptic of his period. ${ }^{26}$ He noticed that tea tree oil was 13 times more active on microorganisms than carbolic acid; since then, the oil started being promoted as therapeutic agent.

The aim of the study was to demonstrate if tea tree oil is really effective and if it could be a suitable alternative to chlorhexidine in treating gingivitis.

\section{Materials and Methods}

\section{Study Design}

The study took place between February and September 2019 in the Local Sanitary Centre of Cisterna di Latina (LT) and included 42 patients affected by dental plaque-induced gingivitis $^{27}$ who attended the hospital and accepted to be involved in the study. The whole group was composed by 30 women and 12 men, aged between 18 and 60 years. The group was then divided into two subgroups: 6 men and 16 women in group A; 6 men and 14 women in group B.

The group of chosen subjects was randomized and controlled. Subjects were assigned to one of the two study groups, using a computer-generated randomization list. Patients were visited (T0) and then followed up after 14 days of domestic treatment (T1). Before beginning the study, patients signed the informed consent, explaining them the treatment they were beginning. The treatment protocol was conformed to the ethical guidelines of the 1975 Declaration of Helsinki and was approved by the Ethics Committee of the Local Sanitary center in Latina (1047/19).

Two different gingivitis treatments acting on domestic oral hygiene were compared in this study. The two treatments differed from each other in the use of different mouthwashes: one tea tree oil-based and the other containing chlorhexidine $0.12 \%$.
After the professional oral hygiene session, patients were divided into two groups:

- Group A: $100 \%$ tea tree oil mouthwash diluted in $100 \mathrm{~mL}$ of water

- Group B: Chlorhexidine 0.12\% mouthwash.

\section{Inclusion Criteria}

- Age more than 18 years.

- At least 20 teeth had to be in the oral cavity, third molars excluded.

- $1<$ gingival index $(\mathrm{GI})<3$.

- $1<$ plaque index $(\mathrm{PI})<3$.

- Bleeding on probing.

- Presence of pseudopockets.

- Absence of clinical attachment loss (CAL).

- Absence of mobility.

- Absence of periodontitis.

- No clear allergy to one of the components of the mouthwashes.

\section{Exclusion Criteria}

- Age less than 18 years.

- Undergoing periodontal treatment in the past 6 months.

- With systemic diseases that could have influenced the therapy (diabetes mellitus, cancer, osteoporosis, radiotherapy, and anticoagulant therapy).

- $\mathrm{CAL}>4 \mathrm{~mm}$.

- With presence of periodontal pockets.

- With mental or physical retardation that could have influenced the domestic oral hygiene.

- Absence of informed consent.

Smoking, pregnancy, and consumption of drugs that cause gum overgrowth were reported, but not considered as exclusion criteria.Clinical Parameters Considered

- Silness-Löe GI.

- Silness-Löe PI and O'leary PI.

- Ainamo and Bay blood index (BI).

- Presence of dental dyschromia: each tooth has been divided into four parts according to the proximal sides. Evaluation has been conducted through dichotomous method: (presence/absence), followed by mean value expressed in percentage.

- Evaluation of taste perception and breath referred by the patient.

\section{Methods}

Each patient was evaluated by the same operator previously trained and calibrated, with each one of them using the same instrument, both at $\mathrm{T} 0$ and $\mathrm{T} 1$.

During the first visit, the following parameters have been registered on a specific periodontal chart: informed consent, anamnesis, GI, PI, BI, probing depth (PD), and presence of eventual lesions or dental dyschromia. Thereafter, 
the subject underwent a professional hygiene session with ultrasounds and Gracey curettes, followed by polishing with rotating instruments and specific paste.

Afterward, a second photo was taken and added to the photographic status of the patient together with the one taken before the hygiene session. The same hygiene instructions were then given to all participants, explaining the single oral situation as documented in literature ${ }^{28}$; to avoid potential bias, a clarification was given to the participants that the study would not have any impact on the quality treatment they sought. Finally, the mouthwash was given. All patients of group A were given a bottle containing $10 \mathrm{~mL}$ of pure tea tree oil for oral use and a plastic dropper. Each patient was asked to include in his routine the administration of $0.65 \mathrm{~mL}$ of product, equal to 9 drops per day. Generally, they were asked to add three drops of tea tree oil to less than half a glass of water after brushing their teeth three times a day. Some patients, due to work-related issues, preferred to take the drops differently, four in the morning after the breakfast and three in the evening always after the oral hygiene procedures. The important point was the consumption of a total of nine drops of tea tree oil per day for 14 days. The patients included in group B were instead given 14 packages of $10 \mathrm{~mL}$ of chlorhexidine $0.12 \%$. Each package contained the daily amount for mouthwashes to be done twice a day. This treatment as well lasted 14 days. The rinsing had to last 60 seconds for both mouthwashes; after the consumption, eating and drinking had to be avoided for at least 30 minutes. After 14 days (T1), patients were recalled for a revaluation. In the second session, GI, PI, BI, and presence of lesions or dental dyschromia were collected again. Thereafter, the photographic examination was updated with a posttreatment picture and a patient observation examination was included through three specific questions: mouthwash taste liking; eventual problems related to its consumption; noticing improvement since the beginning.

The data gathered were recorded with a specially designed computer program and collected in a Microsoft Excel database. Descriptive statistics were computed for each parameter. The analysis of the data was performed using SPSS 14.0 for Windows (SPSS Inc., Chicago, IL, USA).

\section{Results}

Clinical parameters for the two groups collected during the first session are reported in - Table $\mathbf{1}$.

In T0, patients of the two groups showed a significant general situation characterized by presence of plaque and bleeding on probing. Technically, in group A, the mean PI was $57.45 \%$ and the mean BI was $22.20 \%$ for 20 patients. Two pregnant women were then added to these patients, changing the two scores: $53.25 \%$ and $38.41 \%$.

In group B, instead, PI had a mean of $47.69 \%$ and the BI of 20 patients was $32.93 \%$. Initially, percentage means obtained indicated that group A was characterized by a greater deposit of plaque and a greater presence of bleeding on probing, despite the two pregnant patients physiologically showing increased bleeding due to the changing of hormonal values.
Probing was made through Williams probe and the measure in millimeters of the deeper pseudopocket found in the oral cavity of each patient were reported in the table.

GI outlines the prevalence of a moderate inflammatory status with redness, edema, and bleeding on probing in both groups.

After the professional oral hygiene session, hygiene instructions were given to each patient, so that monitoring even the slightest change was easier. First, getting the patient to acknowledge the situation of his oral cavity through a mirror was considered appropriate, so that he was then motivated and instructed for domestic oral hygiene procedures. The latter establishes, where possible, the use of a medium bristles brush with the same toothpaste for all the patients and with the same Bass modified brushing technique. To these medical goods, the specific mouthwash was added for two weeks. At the end of the trial period, patients were once again evaluated (T1) (-Table 2). Once the clinical parameters were collected, it was possible to compare them to the ones measured in the first session ( - Fig. 1). The comparison led to the following findings:

- In both groups, reduced plaque presence as well as reduced bleeding on probing were achieved. In group A, the mean PI decreased to $5.50 \%$, including the two patients in their first trimester of pregnancy; the mean BI was $4.22 \%$.

In group B, the mean PI decreased to $2.37 \%$ and the mean BI was $6.28 \%$.

- In group A, the gum status improved; also, not only bleeding but also redness and edema in the gums decreased (-Fig. 2).

In group B, the gum status improved, but in some cases bleeding on probing and swelling were still present ( - Fig. 3 ).

- The sites with pseudopockets reduced in number and the ones with reversible lesion reduced in millimeters.

- Dental dyschromia due to the administration of the mouthwash was not detected in group A and just four patients (18\%) of 22 complained about nausea during the first days of consumption of tea tree oil, due to the typical smell.

In group $\mathrm{B}$, dental discolorations due to the consumption of chlorhexidine were detected for at least two sides over four of the elements (20\%) and plaque deposit was detected as well ( - Fig. 4). Four patients complained about alteration of taste buds when eating salted and spicy foods. In the end, 12 patients did not like the taste of the mouthwash due to the unpleasant burning sensation.

\section{Discussion}

Gingivitis is the disease that affects, through an inflammatory process caused by bacteria, gum tissues. It is really common and can show up in different phases of the life of an individual. In fact, gingivitis can be determined by stressful situations, drugs, or hormonal changes. ${ }^{29}$ Its etiological factor has proved to be the bacterial component. That is why the 
Table 1 Clinical parameters at T0

\begin{tabular}{|c|c|c|c|c|c|c|}
\hline & Patients & GI & $\mathrm{PI} \%$ & $\mathrm{BI} \%$ & PD mm & $\begin{array}{l}\text { Presence of dental } \\
\text { dyschromia }\end{array}$ \\
\hline 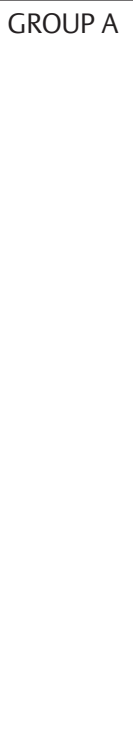 & $\begin{array}{l}1 \\
2 \\
3 \\
4 \\
5 \\
6 \\
7 \\
8 \\
9 \\
10 \\
11 \\
12 \\
13 \\
14 \\
15 \\
16 \\
17 \\
18 \\
19 \\
20 \\
21 \\
22\end{array}$ & $\begin{array}{l}2 \\
2 \\
2 \\
2 \\
1 \\
2 \\
1 \\
1 \\
2 \\
2 \\
2 \\
2 \\
1 \\
1 \\
2 \\
2 \\
2 \\
2 \\
2 \\
2 \\
1 \\
2\end{array}$ & $\begin{array}{l}62.50 \% \\
59.37 \% \\
48.43 \% \\
93.75 \% \\
45.31 \% \\
76.56 \% \\
48.43 \% \\
34.37 \% \\
76.56 \% \\
68.75 \% \\
53.90 \% \\
62.50 \% \\
17.96 \% \\
26.50 \% \\
76.56 \% \\
50.78 \% \\
60.15 \% \\
53.90 \% \\
76.56 \% \\
56.25 \% \\
23.43 \% \\
50.78 \%\end{array}$ & $\begin{array}{l}28.12 \% \\
22.65 \% \\
14.06 \% \\
54.68 \% \\
12.50 \% \\
26.56 \% \\
14 \% \\
6.25 \% \\
31.25 \% \\
30.46 \% \\
18.75 \% \\
23.43 \% \\
6.25 \% \\
7.81 \% \\
26.56 \% \\
18.75 \% \\
22.65 \% \\
27.34 \% \\
35.15 \% \\
18.75 \% \\
34.37 \% \\
58.59 \%\end{array}$ & $\begin{array}{l}3 \\
3 \\
3 \\
3 \\
2 \\
3 \\
1 \\
1 \\
3 \\
4 \\
2 \\
2 \\
0 \\
1 \\
4 \\
3 \\
3 \\
2 \\
4 \\
3 \\
1 \\
3\end{array}$ & $\begin{array}{l}1 \\
1 \\
1 \\
1 \\
1 \\
1 \\
1 \\
1 \\
1 \\
1 \\
1 \\
1 \\
1 \\
1 \\
1 \\
\text { Fluorosis } \\
1 \\
1 \\
1 \\
1 \\
1 \\
\text { I }\end{array}$ \\
\hline GROUP B & $\begin{array}{l}1 \\
2 \\
3 \\
4 \\
5 \\
6 \\
7 \\
8 \\
9 \\
10 \\
11 \\
12 \\
13 \\
14 \\
15 \\
16 \\
17 \\
18 \\
19 \\
20\end{array}$ & $\begin{array}{l}2 \\
2 \\
2 \\
2 \\
1 \\
1 \\
2 \\
2 \\
1 \\
1 \\
2 \\
2 \\
2 \\
2 \\
1 \\
2 \\
2 \\
1 \\
1 \\
2\end{array}$ & $\begin{array}{l}62.50 \% \\
71.87 \% \\
43.75 \% \\
66.40 \% \\
17.96 \% \\
25 \% \\
71.87 \% \\
53.90 \% \\
19.53 \% \\
25 \% \\
53.90 \% \\
68.75 \% \\
59.37 \% \\
76.56 \% \\
21.87 \% \\
53.90 \% \\
50.78 \% \\
32.81 \% \\
28.12 \% \\
50 \%\end{array}$ & $\begin{array}{l}66.40 \% \\
43.75 \% \\
22.65 \% \\
53.12 \% \\
12.50 \% \\
7.81 \% \\
62.50 \% \\
45.31 \% \\
19.53 \% \\
6.44 \% \\
25 \% \\
43.75 \% \\
40.62 \% \\
46.09 \% \\
19.53 \% \\
35.93 \% \\
48.43 \% \\
15.62 \% \\
23.43 \% \\
20.31 \%\end{array}$ & $\begin{array}{l}3 \\
4 \\
3 \\
4 \\
1 \\
2 \\
4 \\
3 \\
2 \\
2 \\
3 \\
3 \\
3 \\
3 \\
1 \\
2 \\
2 \\
1 \\
1 \\
3\end{array}$ & $\begin{array}{l}\text { I } \\
1 \\
1 \\
1 \\
1 \\
1 \\
1 \\
1 \\
\text { I White spot } \\
\text { I } \\
\text { I } \\
\text { I } \\
\text { I } \\
\text { I White spot } \\
\text { I } \\
\text { I } \\
\text { I } \\
\text { I }\end{array}$ \\
\hline
\end{tabular}

Abbreviations: BI, bleeding index; $\mathrm{Gl}$, gingival index; PD, probing depth; PI, plaque index.

treatment of choice is a professional oral hygiene procedure that allows removal of the etiologic factor. At the same time, domestic oral hygiene is fundamental, so that bacteria will not colonize gingival tissues again and inflammation will not show up again. ${ }^{30}$

Among the medical products recommended for the cure of gingivitis, chlorhexidine-based mouthwash is included. In fact, chlorhexidine is a synthetic biguanide cationic molecule with a strong bactericidal and bacteriostatic action. However, if its use is prolonged, it can cause dental dyschromia, taste alteration, and plaque deposit. ${ }^{31}$

That is why, over the last decades, researchers looked for an alternative to this molecule, so that gingivitis could be cured without any limitation or complication, due to the use of the medication over time. ${ }^{32}$ Tea tree oil is an essential oil that was recently discovered and introduced into the oral hygiene world. It has always been used as excellent substance in healing herpetic lesions or mouth ulcers by virtue of its antibacterial and antiviral properties. ${ }^{13,33}$ The study aims at demonstrating the efficacy of a new natural Melaleuca essential oil-based substance, both for the control of dental plaque and inflammatory response in comparison to chlorhexidine. Based on the results achieved, it can be stated that both substances are effective in treating gingivitis through a treatment realized in 14 days. Furthermore, tea tree oil proved to be a suitable substitute of chlorhexidine not much for its antibacterial action, but more in reducing PD and clinical signs of inflammation.

Furthermore, the subjects of the trial better appreciated tea tree oil's typical taste compared with that of chlorhexidine, improving also the breath, especially when used first thing in the morning. All participants accomplished this without any taste alteration, dental dyschromia, or plaque deposit.

Just few experimental trials regarding the use of this essential oil in treating gingivitis were performed. ${ }^{17,34,35}$ In spite of this, clear results were obtained, and they reflected and confirmed the investigation performed in this article. 
Table 2 Clinical parameters at T1

\begin{tabular}{|c|c|c|c|c|c|c|}
\hline & Patients & GI & $\mathrm{PI} \%$ & $\mathrm{BI} \%$ & PD mm & $\begin{array}{l}\text { Presence of dental } \\
\text { dyschromia }\end{array}$ \\
\hline GROUP A & $\begin{array}{l}1 \\
2 \\
3 \\
4 \\
5 \\
6 \\
7 \\
8 \\
9 \\
10 \\
11 \\
12 \\
13 \\
14 \\
15 \\
16 \\
17 \\
18 \\
19 \\
20 \\
21 \\
22\end{array}$ & $\begin{array}{l}1 \\
0 \\
0 \\
1 \\
0 \\
0 \\
0 \\
0 \\
1 \\
1 \\
0 \\
0 \\
0 \\
0 \\
0 \\
0 \\
0 \\
0 \\
1 \\
0 \\
1 \\
1\end{array}$ & $\begin{array}{l}19.53 \% \\
6.25 \% \\
12.50 \% \\
6.25 \% \\
1.56 \% \\
3.12 \% \\
3.12 \% \\
2.34 \% \\
12.50 \% \\
3.12 \% \\
6.25 \% \\
5.46 \% \\
3.12 \% \\
4.68 \% \\
1.56 \% \\
3.90 \% \\
1.56 \% \\
5.46 \% \\
9.37 \% \\
4.68 \% \\
1.56 \% \\
3.12 \%\end{array}$ & $\begin{array}{l}15.62 \% \\
1.56 \% \\
1.56 \% \\
12.50 \% \\
0 \\
0 \\
1.56 \% \\
2.34 \% \\
14.06 \% \\
18.75 \% \\
1.56 \% \\
0 \\
0 \\
0 \\
0 \\
0 \\
0 \\
1.56 \% \\
12.50 \% \\
0 \\
3.12 \% \\
6.25 \%\end{array}$ & $\begin{array}{l}2 \\
0 \\
1 \\
2 \\
0 \\
0 \\
0 \\
0 \\
2 \\
2 \\
1 \\
0 \\
1 \\
0 \\
0 \\
1 \\
0 \\
0 \\
1 \\
0 \\
1 \\
1\end{array}$ & $\begin{array}{l}1 \\
1 \\
1 \\
1 \\
1 \\
1 \\
1 \\
1 \\
1 \\
1 \\
1 \\
1 \\
1 \\
1 \\
1 \\
1 \\
1 \\
1 \\
1 \\
1 \\
1 \\
1\end{array}$ \\
\hline GROUP B & $\begin{array}{l}1 \\
2 \\
3 \\
4 \\
5 \\
6 \\
7 \\
8 \\
9 \\
10 \\
11 \\
12 \\
13 \\
14 \\
15 \\
16 \\
17 \\
18 \\
19 \\
20\end{array}$ & $\begin{array}{l}1 \\
1 \\
0 \\
2 \\
1 \\
0 \\
2 \\
1 \\
0 \\
0 \\
1 \\
1 \\
2 \\
1 \\
1 \\
1 \\
2 \\
0 \\
1 \\
1\end{array}$ & $\begin{array}{l}2.34 \% \\
1.56 \% \\
0 \\
9.37 \% \\
6.25 \% \\
0 \\
10.93 \% \\
9.37 \% \\
1.56 \% \\
0 \\
2.34 \% \\
4.68 \% \\
3.12 \% \\
1.56 \% \\
1.56 \% \\
4.68 \% \\
3.12 \% \\
1.56 \% \\
0 \\
1.56 \%\end{array}$ & $\begin{array}{l}12.50 \% \\
10.93 \% \\
1.56 \% \\
21.87 \% \\
3.12 \% \\
3.12 \% \\
9.37 \% \\
6.25 \% \\
3.12 \% \\
2.34 \% \\
1.56 \% \\
1.56 \% \\
10.93 \% \\
13.28 \% \\
2.34 \% \\
6.25 \% \\
14.06 \% \\
1.56 \% \\
0 \\
0\end{array}$ & $\begin{array}{l}2 \\
2 \\
1 \\
2 \\
1 \\
0 \\
3 \\
2 \\
0 \\
0 \\
2 \\
2 \\
3 \\
2 \\
2 \\
1 \\
2 \\
0 \\
0 \\
0\end{array}$ & 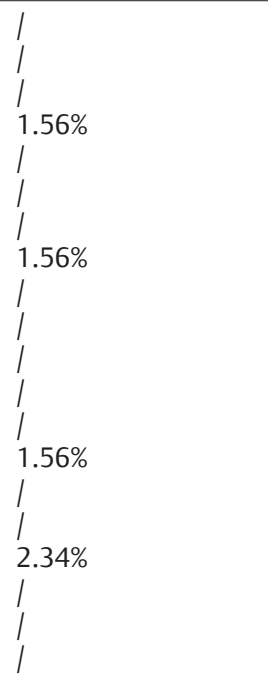 \\
\hline
\end{tabular}

Abbreviations: $\mathrm{Bl}$, bleeding index; $\mathrm{Gl}$, gingival index; $\mathrm{PD}$, probing depth; $\mathrm{Pl}$, plaque index.

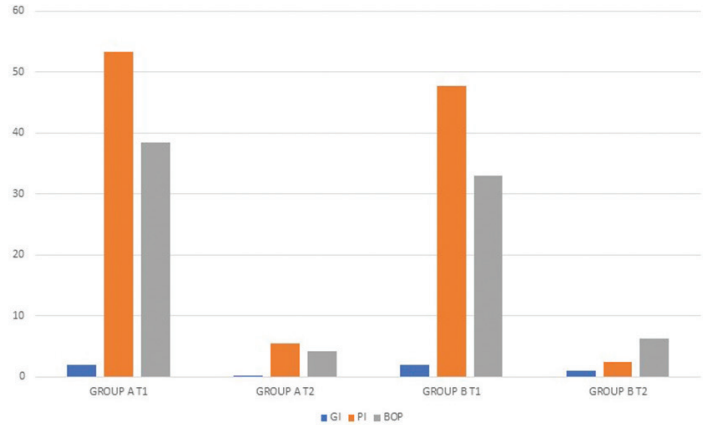

Fig. 1 Comparison between oral hygiene sessions.

In accordance with the studies of Salvatori et al, ${ }^{17}$ Soukoulis et $\mathrm{al}^{34}$ and Saxer et $\mathrm{al}^{35}$ tea tree oil proved to be a concrete agent with anti-inflammatory and antibacterial actions.
In Salvatori's research, ${ }^{17}$ despite the small number of subjects analyzed, the same improvements of this study in question were obtained, but in different percentages. In fact, the powerful and greater efficacy of the anti-inflammatory function of tea tree oil compared with other mouthwashes was confirmed. In both cases, essential oil reduced bleeding in the sites detected during the first session, improving GI when characterized by moderate or severe inflammation (grade 2-3), mild inflammation (grade 1), or even absence of inflammation (grade 0 ). The same beneficial effect was demonstrated in a study by Soukoulis et al, ${ }^{34}$ investigating 49 nonsmoking patients affected by severe chronic gingivitis. Concerning the antibacterial effect, in all the studies, tea tree oil showed to be a potential reducer of the bacterial load, but not the most powerful and effective. In fact, chlorhexidine remains the most incisive substance for the reduction of periodontopathogens bacteria that represent the etiologic factor of the disease. ${ }^{36}$ In the above-mentioned studies, dental 

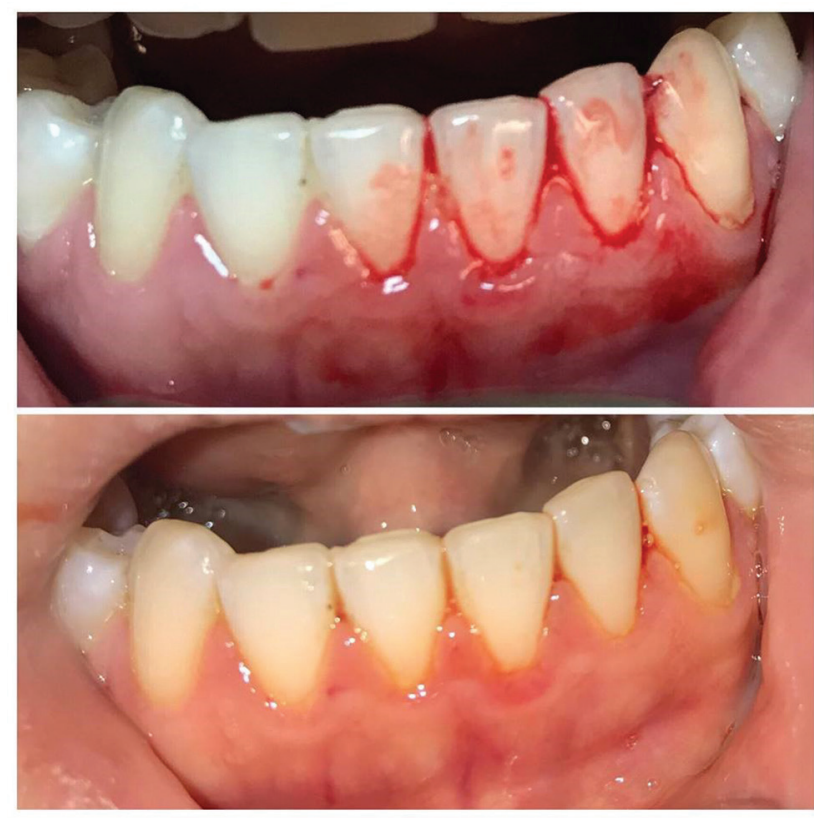

Fig. 2 Subject from Group A: pre- and posttreatment.
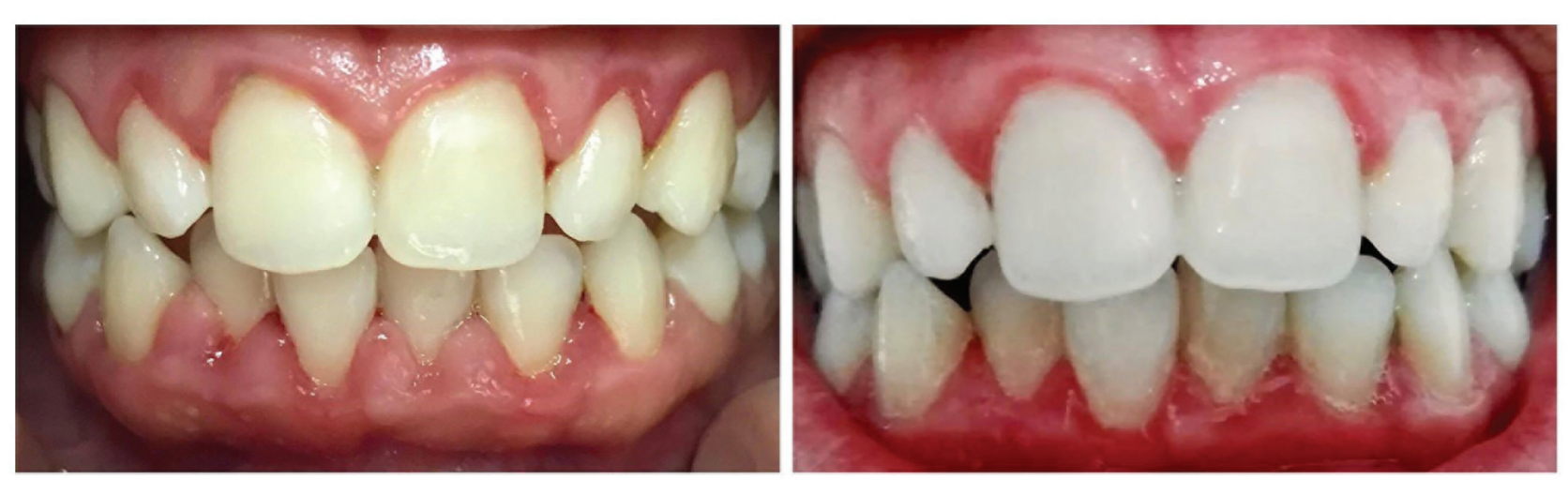

Fig. 3 Subject from Group B: pre- and posttreatment.
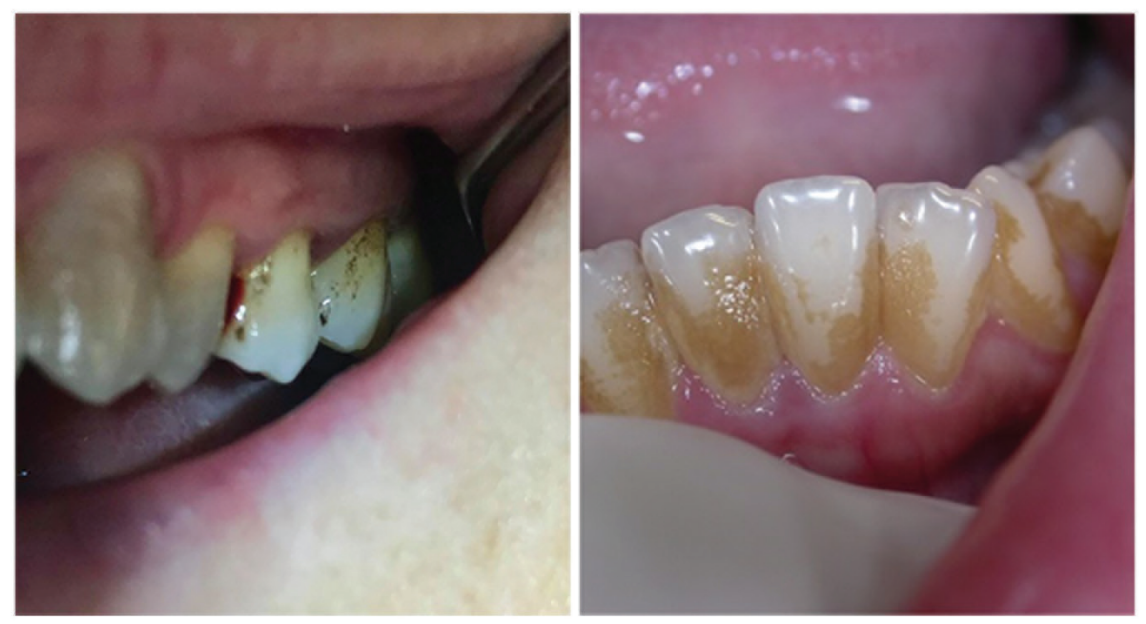

or gum dyschromia was not detected. But, as many studies demonstrated, one of the complications of this powerful antiseptic is exactly the coloration of dental surfaces, generally detected after a long period of treatment..$^{31}$ That is why it has to be reiterated how tea tree oil, despite a minor efficacy, can still reduce or control the bacterial load without causing nor dyschromia or taste alteration; in fact, all the patients undergoing the treatment with the essential oil complained about nothing in any study. Everything should be considered without leaving out the eventual conditioning of a poor or wrong domestic oral hygiene realized by the patient. At the end of the revaluation session, no toxicity manifestation due to the consumption was shown; the two pregnant patients are an example of this affirmation, given that they did not report any disturb. As reported by the study realized by Hammer et $\mathrm{al}^{37}$ it was discovered that the topical use of the product is safe and that complications are random. The data published in this study refer to the presence of toxicity if the product is ingested in massive doses (1.9 per kg of weight).

Furthermore, in this study, the product was not ingested, but administered through rinses of drops diluted in water, so

Fig. 4 Posttreatment dental dyschromia in subjects from Group B. 
it was assimilated in a very small daily amount without being toxic. Unfortunately, in this trial, just two pregnant women were analyzed. They underwent the treatment with tea tree oil under the supervision of a professional figure; they did not show any complication in the revaluation session. This, as well, is due to the minimal quantity of the product assimilated during the phase of treatment. It is always important to recommend the patient to store the product in a dry and cool place and far from sun rays, not altering its composition.

To better understand its dynamics, it would be appropriate to further explore the study, thereby increasing the number of samples of pregnant or breastfeeding subjects.

\section{Conclusions}

The study proposed needs to be considered as a pilot study because of limited number of patients and brief follow-up. To obtain statistically more relevant and defined data, it would be advantageous to carry out additional studies to determine tea tree oil's global action and discover additional substitutes. The results obtained are very promising and it is recommended to further this research to treat gingivitis by comparing tea tree oil mouthwash to ammine fluoride-stannous fluoride mouthwash ${ }^{38}$ or chlorhexidine with cetylpyridinium chloride mouthwash. ${ }^{39}$ The results suggest that tea tree oil could be advantageous in cases where patients spend little time on toothbrushing. Further clinical studies are required to evaluate the action of this herbal agent in other oral diseases such as chronic periodontitis.

\section{Conflict of Interest}

None declared.

\section{References}

1 Germano F, Bramanti E, Arcuri C, Cecchetti F, Cicciù M. Atomic force microscopy of bacteria from periodontal subgingival biofilm: Preliminary study results. Eur J Dent 2013;7(2):152-158

2 Fiorillo L, Cervino G, Laino L, et al. Porphyromonas gingivalis, periodontal and systemic implications: a systematic review. Dent J (Basel) 2019;7(4):E114

3 James P, Worthington HV, Parnell C, et al. Chlorhexidine mouthrinse as an adjunctive treatment for gingival health. Cochrane Database Syst Rev 2017;3:CD008676

4 Little JW. Complementary and alternative medicine: impact on dentistry. Oral Surg Oral Med Oral Pathol Oral Radiol Endod 2004;98(2):137-145

5 Ercan N, Erdemir EO, Ozkan SY, Hendek MK. The comparative effect of propolis in two different vehicles; mouthwash and chewing-gum on plaque accumulation and gingival inflammation. Eur J Dent 2015;9(2):272-276

6 Carvalho C, Fernandes WHC, Mouttinho TBF, Souza DM, Marcucci MC, D'Alpino PH. Evidence-based studies and perspectives of the use of Brazilian green and red propolis in dentistry. Eur J Dent 2019;13(3):459-465

7 Cicciù M, Fiorillo L, Cervino G. Chitosan use in dentistry: a systematic review of recent clinical studies. Mar Drugs 2019;17(7):E417
8 Manion CR, Widder RM. Essentials of essential oils. Am J Health Syst Pharm 2017;74(9):e153-e162

9 Gnatta JR, Pinto FM, Bruna CQ, Souza RQ, Graziano KU, Silva MJ. Comparison of hand hygiene antimicrobial efficacy: Melaleuca alternifolia essential oil versus triclosan. Rev Lat Am Enfermagem 2013;21(6):1212-1219

10 Budzyńska A, Wieckowska-Szakiel M, Sadowska B, Kalemba D, Rózalska B. Antibiofilm activity of selected plant essential oils and their major components. Pol J Microbiol 2011;60(1):35-41

11 Carson CF, Hammer KA, Riley TV. Melaleuca alternifolia (tea tree) oil: a review of antimicrobial and other medicinal properties. Clin Microbiol Rev 2006;19(1):50-62

12 Groppo FC, Ramacciato JC, Simões RP, Flório FM, Sartoratto A. Antimicrobial activity of garlic, tea tree oil, and chlorhexidine against oral microorganisms. Int Dent J 2002;52(6):433-437

13 Carson CF, Ashton L, Dry L, Smith DW, Riley TV. Melaleuca alternifolia (tea tree) oil gel (6\%) for the treatment of recurrent herpes labialis. J Antimicrob Chemother 2001;48(3):450-451

14 Calcabrini A, Stringaro A, Toccacieli L, et al. Terpinen-4-ol, the main component of Melaleuca alternifolia (tea tree) oil inhibits the in vitro growth of human melanoma cells. J Invest Dermatol 2004;122(2):349-360

15 Bozzuto G, Colone M, Toccacieli L, Stringaro A, Molinari $A$. Tea tree oil might combat melanoma. Planta Med 2011;77(1):54-56

16 Casarin M, Pazinatto J, Santos RCV, Zanatta FB. Melaleuca alternifolia and its application against dental plaque and periodontal diseases: a systematic review. Phytother Res 2018;32(2):230-242

17 Salvatori C, Barchi L, Guzzo F, Gargari M. A comparative study of antibacterial and anti-inflammatory effects of mouthrinse containing tea tree oil. Oral Implantol (Rome) 2017;10(1):59-70

18 Syed TA, Qureshi ZA, Ali SM, Ahmad S, Ahmad SA. Treatment of toenail onychomycosis with $2 \%$ butenafine and $5 \%$ Melaleuca alternifolia (tea tree) oil in cream. Trop Med Int Health 1999;4(4):284-287

19 Takarada K, Kimizuka R, Takahashi N, Honma K, Okuda K, Kato T. A comparison of the antibacterial efficacies of essential oils against oral pathogens. Oral Microbiol Immunol 2004;19(1):61-64

20 Warnke PH, Sherry E, Russo PA, et al. Antibacterial essential oils reduce tumor smell and inflammation in cancer patients. J Clin Oncol 2005;23(7):1588-1589

21 Pazyar N, Yaghoobi R, Bagherani N, Kazerouni A. A review of applications of tea tree oil in dermatology. Int J Dermatol 2013;52(7):784-790

22 Di Vito M, Mattarelli P, Modesto M, et al. In vitro activity of tea tree oil vaginal suppositories against Candida SPP and probiotic vaginal microbiota. Phytother Res 2015;29(10):1628-1633

23 Buck DS, Nidorf DM, Addino JG. Comparison of two topical preparations for the treatment of onychomycosis: Melaleuca alternifolia (tea tree) oil and clotrimazole. J Fam Pract 1994;38(6):601-605

24 Elliott C. Tea tree oil poisoning. Med J Aust 1993;159(11-12):830-831

25 de Groot AC, Weyland JW. Systemic contact dermatitis from tea tree oil. Contact Dermat 1992;27(4):279-280

26 Penfold AR, Morrison FR. Recent developments in Australian essential oils. Australas J Pharm 1946;27(321):723

27 Chapple ILC, Mealey BL, Van Dyke TE, et al. Periodontal health and gingival diseases and conditions on an intact and a reduced periodontium: Consensus report of workgroup 1 of the 2017 World Workshop on the Classification of Periodontal and Peri-Implant Diseases and Conditions. J Periodontol 2018;89(Suppl 1):S74-S84 
28 Claydon NC. Current concepts in toothbrushing and interdental cleaning. Periodontol 2000 2008;48:10-22

29 Loe $\mathrm{H}$, Theilade E, Jensen SB. Experimental gingivitis in man. J Periodontol 1965;36:177-187

30 Tatakis DN, Trombelli L. Modulation of clinical expression of plaque-induced gingivitis. I. Background review and rationale. J Clin Periodontol 2004;31(4):229-238

31 Jones CG. Chlorhexidine: is it still the gold standard? Periodontol 2000 1997; 15:55-62

32 Kamath NP, Tandon S, Nayak R, Naidu S, Anand PS, Kamath YS. The effect of aloe vera and tea tree oil mouthwashes on the oral health of school children. Eur Arch Paediatr Dent 2019. doi: 10.1007/s40368-019-00445-5

33 Arweiler NB, Donos N, Netuschil L, Reich E, Sculean A. Clinical and antibacterial effect of tea tree oil-a pilot study. Clin Oral Investig 2000;4(2):70-73

34 Soukoulis $\mathrm{S}$, Hirsch R. The effects of a tea tree oil-containing gel on plaque and chronic gingivitis. Aust Dent J 2004;49(2):78-83
35 Saxer UP, Stäuble A, Szabo SH, Menghini G. Effect of mouthwashing with tea tree oil on plaque and inflammation [article in French, German]. Schweiz Monatsschr Zahnmed 2003;113(9):985-996

36 Fiorillo L. Chlorhexidine gel use in the oral district: a systematic review. Gels 2019;5(2):E31

37 Hammer KA, Carson CF, Riley TV, Nielsen JB. A review of the toxicity of Melaleuca alternifolia (tea tree) oil. Food Chem Toxicol 2006;44(5):616-625

38 Quaranta A, Ronconi LF, Di Carlo F, Vozza I, Quaranta M. Electrochemical behaviour of titanium in ammine and stannous fluoride and chlorhexidine 0.2 percent mouthwashes. Int J Immunopathol Pharmacol 2010;23(1):335-343

39 Guerra F, Pasqualotto D, Rinaldo F, et al. Therapeutic efficacy of chlorhexidine-based mouthwashes and its adverse events: Performance-related evaluation of mouthwashes added with Anti-Discoloration System and cetylpyridinium chloride. Int J Dent Hyg 2019;17(3):229-236 